\title{
Short and long term outcome of Helicobacter pylori positive resistant duodenal ulcers treated with colloidal bismuth subcitrate plus antibiotics or sucralphate alone
}

\author{
G Bianchi Porro, F Parente, M Lazzaroni
}

\begin{abstract}
Thirty two patients with Helicobacter pylori positive duodenal ulcers resistant to treatment were randomly assigned to 4 weeks' treatment with sucralphate $4 \mathrm{~g} /$ day or colloidal bismuth subcitrate $480 \mathrm{mg} /$ day plus amoxycillin from days 1 to 7 and tinidazole from days 8 to 14 . After 4 weeks, patients with unhealed ulcers were crossed over to the other form of treatment for a further 4 week period. Patients with healed ulcers were followed up for 1 year without maintenance therapy with clinical and endoscopic investigations 3,6 , and 12 months after healing. Complete healing rates at 4 weeks were $88 \%$ (15 of 17 ) in the colloidal bismuth subcitrate plus antibiotics group and $40 \%$ (six of 15) in the sucralphate group $(\mathbf{p}<0.05)$. After cross over, overall healing rates were $88 \%$ (22 of 25 ) and $47 \%$ (eight of 17 ), respectively $(\mathrm{p}<0.05)$. $H$ pylori eradication occurred in $83 \%$ of patients treated with the triple therapy. Cumulative relapse rates at $\mathbf{1 2}$ months were $12 \%$ (two of 17) in patients in whom $H$ pylori had been eradicated and $100 \%$ $(10$ of 10$)$ in those with persistent infection after short term therapy $(\mathbf{p}<\mathbf{0 . 0 5})$. These results show that a colloidal bismuth subcitrate plus antibiotics regimen is highly effective in the short term treatment of resistant duodenal ulcers and that $H$ pylori eradication can change the natural tendency to early recurrence of these ulcers.
\end{abstract}

(Gut 1993; 34: 466-469)

Duodenal ulcers that are resistant to $\mathrm{H}_{2}$ blockers are a relatively uncommon condition of unknown aetiology that nowadays can be managed effectively by medical treatment. ${ }^{1}$ Two drugs can be considered, colloidal bismuth subcitrate and omeprazole, both of which produce healing rates of $80 \%$ or more within 4 weeks of treatment..$^{2-8}$ The reasons for the high efficacy of colloidal bismuth subcitrate in these patients are not well known. One suggestion is the antimicrobial effectiveness of the drug against Helicobacter pylori, since two recent trials have shown that the combination of $\mathrm{H}_{2}$ antagonists and drugs that are active against $H$ pylori (ofloxacin and bismuth subsalicylate respectively) is highly effective in healing these ulcers. ${ }^{910}$ Unfortunately, the role of $H$ pylori was not investigated in the two controlled trials conducted on colloidal bismuth subcitrate in resistant duodenal ulcers. ${ }^{23}$

In addition, long term treatment remains an unsolved problem in the management of resistant duodenal ulcers. Once finally healed, these ulcers tend to recur early, despite continuous maintenance treatment with reduced or full doses of $\mathrm{H}_{2}$ blockers. ${ }^{411}$ Although the influence of $H$ pylori infection on duodenal ulcer relapse is widely known, this is the first study to evaluate the effect of $H$ pylori eradication on the long term outcome of patients with refractory duodenal ulcers.

The purpose of the present study was twofold: firstly, to compare the efficacy of an antiulcer treatment regimen able to eradicate $H$ pylor $i$ with that of a drug with similar antiulcer action but virtually devoid of anti- $H$ pylori activity, in promoting the healing of $H$ pylori positive resistant duodenal ulcers and, secondly, to investigate whether $H$ pylori eradication can change the natural tendency towards early recurrence of these ulcers.

\section{Patients and methods}

Initial recruitment was made between November 1989 and October 1991 among outpatients with endoscopically proved duodenal ulcers who were monitored endoscopically in our unit after 8 weeks of treatment with full doses of $\mathrm{H}_{2}$ blockers. All patients with unhealed ulcers of $5 \mathrm{~mm}$ minimum and $3 \mathrm{~cm}$ maximum diameter and $H$ pylori antral infection (documented by rapid urease test or histology, or both) were considered eligible for the study if one examiner judged their compliance with previous treatment to be good.

Thirty two of 35 patients ( 18 men, 14 women) who had failed to respond to $\mathrm{H}_{2}$ antagonists (21 patients to ranitidine $300 \mathrm{mg} /$ day and 11 to famotidine $40 \mathrm{mg} /$ day) met these criteria and were enrolled in the study. They had not had previous gastric surgery nor did they have any concomitant major medical problems such as cardiac, pulmonary, hepatic or renal insufficiencies. None had pyloric stenosis or concomitant gastric ulcer, nor did they have acid secretion values or serum fasting gastrin concentrations in the range of the Zollinger-Ellison syndrome. Indeed, in all patients the fasting serum gastrin (Becton Dickinson, Orangeburg, New York) and maximal acid output after stimulation with pentagastrin $(6 \mu \mathrm{g} / \mathrm{kg})$ had been determined at initial diagnosis.

The total population of patients with ulcers from which this series was recruited could not be determined as in a few patients the initial diagnosis of ulcer was not established in our unit. A measure of the magnitude of resistant duo- 
denal ulcers in our population can be drawn, however, from a previous study of ours in which the frequency of refractoriness to an 8 week treatment course with ranitidine was $7 \%$. $^{2}$

After obtaining permission from the local ethical committee and informed verbal consent from the patients, they were allocated, according to a randomised list of 40 subjects, to either colloidal bismuth subcitrate $480 \mathrm{mg} /$ day (one tablet half an hour before the three main meals and at bedtime) for 4 weeks plus amoxicillin $1.0 \mathrm{~g}$ orally three times daily for the first week and tinidazole $500 \mathrm{mg}$ orally twice daily from day 8 to day 14 , or to sucralphate $4 \mathrm{~g} /$ day (one tablet half an hour before breakfast, lunch, and dinner and at bedtime) for 4 weeks. An endoscopic control examination was performed afterwards. If the ulcer was healed - that is, there was complete resolution of the ulcer crater - at 4 weeks, the acute phase was deemed to have ended and the patient entered the long term phase. If the ulcer was not healed at 4 weeks, the patient was crossed over to the other form of treatment for another 4 weeks and subsequently reassessed by endoscopy.

$H$ pylori status was evaluated by both the rapid urease test and histology at each endoscopic investigation. In particular, at least two antral biopsy specimens for histological identification and one for urease test were taken within $3-5 \mathrm{~cm}$ of the pylorus by means of standard sized biopsy forceps. Eradication was defined as the inability to detect $H$ pylori by means of histology and a urease test 1 month after ending treatment.

No other medication was given during the study period with the exception of antacids for relief of pain. Compliance was ascertained by recording the number of unused tablets returned by the patient at the end of each treatment period. If, after 8 weeks, the ulcer had not healed the patient was withdrawn from the trial. Sequential antibiotic treatment (instead of using them all at once) was chosen since in our experience this improves patient compliance (by

TABLE I Individual characteristics of patients enrolled in the study

\begin{tabular}{lcc}
\hline & $\begin{array}{l}\text { Colloidal bismuth } \\
\text { subcitrate plus } \\
\text { antibiotics }\end{array}$ & Sucralphate \\
\hline No of patients & 17 & 15 \\
Male:female & $8 / 9$ & $10 / 5$ \\
Age (y) (mean (SD)) & $44 \cdot 7(10 \cdot 7)$ & $48 \cdot 7(12 \cdot 4)$ \\
Duration of disease (mth) (mean (SD)) & $144 \cdot 0(83 \cdot 1)$ & $123 \cdot 5(97 \cdot 5)$ \\
Smokers (\%) & 71 & 54 \\
Maximal acid output (mmol/h)(mean (SD)) & $38 \cdot 8(9 \cdot 1)$ & $43 \cdot 5(11 \cdot 5)$ \\
Fasting gastrin (pg/ml) (mean (SD)) & $56 \cdot 5(23 \cdot 1)$ & $54 \cdot 2(17 \cdot 3)$ \\
Longest ulcer diameter (mm)(mean (SD)) & $9 \cdot 2(2 \cdot 5)$ & $7 \cdot 4(2 \cdot 7)$ \\
Refractoriness to: & 12 & 9 \\
$\quad$ ranitidine (no) & 5 & 6 \\
$\quad$ famotidine (no) & $1 \cdot 6(0 \cdot 5)$ & $1 \cdot 3(0 \cdot 6)$ \\
No of recurrences over the last 12 months (mean (SD)) & & \\
\hline
\end{tabular}

TABLE II Endoscopic healing rates and Helicobacter pylori status with the two different treatment regimens

\begin{tabular}{|c|c|c|c|}
\hline & $\begin{array}{l}\text { Colloidal bismuth } \\
\text { subcitrate plus } \\
\text { antibiotics }\end{array}$ & Sucralphate & $95 \% C I$ \\
\hline $\begin{array}{l}\text { Healing at } 4 \text { weeks } \\
\text { Healing at } 8 \text { weeks } \\
\text { Cumulative healing } \\
H \text { pylori clearance } \\
H \text { pylori eradication }\end{array}$ & $\begin{array}{l}15 / 17(88 \%) \\
7 / 8 \\
22 / 25(88 \%) \\
25 / 25(100 \%)\end{array}$ & $\begin{array}{l}6 / 15(40 \%) \\
2 / 2 \\
8 / 17(47 \%) \\
1 / 6(17 \%)\end{array}$ & $\begin{array}{l}+0.15,+0.83 \\
+0.12,+0.73\end{array}$ \\
\hline (1 month after healing) & $20 / 24(83 \%)$ & $0 / 6$ & \\
\hline
\end{tabular}

reducing the number of tablets to be taken per day) without affecting anti-H pylori activity (unpublished observation).

All patients with a healed ulcer after the short term phase entered a follow up study lasting 12 months. No maintenance therapy was given and patients were cautioned not to take antibiotics, antacids, or bismuth containing drugs. Endoscopy with histology and rapid urease test was repeated $1,3,6$, and 12 months after treatment was stopped, or before if ulcer symptoms recurred. Patients were withdrawn from the study if they had an ulcer relapse at any time after stopping treatment or if they remained ulcer free and completed the follow up period.

\section{STATISTICS}

Statistical analysis of the results was performed by means of Fisher's exact test and Student's $t$ test for unpaired samples for the acute phase; $\mathbf{9 5 \%}$ confidence intervals for differences in healing rates were also calculated. Differences in relapse rates between $H$ pylori positive and negative patients were evaluated by the KaplanMeier method. Statistical significance was calculated by the log rank test.

\section{Results}

Of the 32 patients who entered the trial, 17 received colloidal bismuth subcitrate and antibiotics and 15 sucralphate. The characteristics of these patients are given in Table I. The two treatment groups did not differ significantly with regard to sex ratio, mean age, mean duration of ulcer disease, number of smokers, maximal acid output, fasting serum gastrin concentration, and their longest ulcer diameter, or in respect of ineffective $\mathrm{H}_{2}$ blockade or their mean number of recurrences over the previous 12 months. No patient defaulted, and drug compliance was good for both groups - never less than $75 \%$.

Endoscopic evaluation after 4 weeks showed that ulcer healing had occurred in $88 \%$ (15 of 17) of patients on colloidal bismuth subcitrate plus antibiotics and $40 \%$ (six of 15 ) of those treated with sucralphate alone $(\mathrm{p}<0.05)$. After the subsequent cross over phase, the cumulative healing rates were again significantly higher in the colloidal bismuth subcitrate plus antibiotics than in the sucralphate group ( $88 \% v 47 \%)$ (Table II).

One month after stopping treatment, histology and rapid urease test failed to detect $H$ pylori in 20 of the $30(66 \%)$ healed patients, all of whom had received the triple therapy. Seventeen of the 20 patients in whom $H$ pylori had been eradicated completed the follow up study correctly. Among these, there were only two ulcer relapses within the following 12 months, whereas all 10 patients who were positive for $H$ pylori 1 month after stopping treatment had endoscopically confirmed duodenal ulcer recurrence during that time (Figure). The difference in relapse rates between $H$ pylori positive and negative groups was statistically significant $(p<0 \cdot 05)$. All but one of the ulcer free patients was still negative for $H$ pylori at the end of the follow up period, whereas in the two patients who were $H$ pylori negative after the 


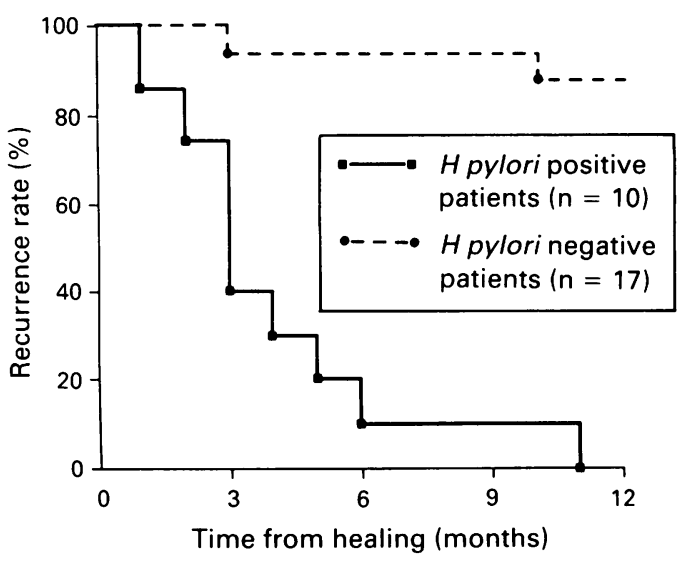

Recurrence rates according to Helicobacter pylori status after short term therapy

acute phase and subsequently relapsed, bacterial reinfection was documented at the time of ulcer recurrence. With regard to the remaining three $H$ pylori negative patients entered in the chronic phase and excluded from the analysis, two did not return after the 3 month examination, at which time the ulcer was still in remission and they remained $H$ pylori free. The third moved abroad and was therefore lost to follow up after the 6 month follow up at which time he was $H$ pylori negative and the ulcer had not recurred.

\section{Discussion}

Although there is a growing body of evidence showing that eradication of $H$ pylori infection is associated with a significant reduction in duodenal ulcer recurrence, ${ }^{12-15}$ no study to date has investigated the role of this organism in both the short and long term outcome of patients with resistant duodenal ulcers.

In our experience, a specifically designed treatment regimen for $H$ pylori infection significantly accelerated the healing of resistant duodenal ulcers and reduced their tendency to relapse compared with a treatment with similar antiulcer action but virtually no anti- $H$ pylori activity. The main explanation for this could be the bactericidal action of the triple therapy against $H$ pylori. This is supported by the observation that the loss of antral $H$ pylori after short term therapy was associated with an increased rate of healing - at 4 weeks healing occurred in 16 of 18 patients $(89 \%)$ who lost antral $H$ pylori but in only five of $14(36 \%)$ with persistent infection. These results agree with those reported recently by Bayerdorffer $e t a l^{9}$ and Wagner $e t a l^{10}$ in refractory duodenal ulcer, as well as by Graham et $a l^{16}$ in non-resistant duodenal ulcer patients, and suggest that adding anti- $H$ pylori agents to an antiulcer regimen may be particularly useful in accelerating the healing of resistant ulcers.

Different effects of the drugs used, however, other than their known bactericidal action on $H$ pylori, cannot be excluded with certainty in explaining the higher healing capacity of the triple therapy. Firstly, colloidal bismuth subcitrate may, by itself, be superior to sucralphate in the treatment of patients with refractory duodenal ulcer, despite similar antiulcer activity. Indeed, healing rates registered at both 4 and 8 weeks in patients taking colloidal bismuth subcitrate plus antibiotics are comparable with those observed in previous studies with colloidal bismuth subcitrate alone, ${ }^{23}$ despite the fact that bismuth preparations by themselves are known to be unsatisfactory for $H$ pylori eradication. ${ }^{17}$ On the other hand, in the only existing controlled trial in which colloidal bismuth subcitrate was compared with sucralphate in non-resistant duodenal ulcers, healing rates were significantly higher in patients treated with colloidal bismuth subcitrate at both 4 and 8 weeks of treatment. ${ }^{18}$ Secondly, antibiotics (for example, metronidazole), in addition to affecting $H$ pylori, may contribute to the healing of ulcers by a direct antiulcer action. Indeed, some antibiotics have been shown to exert antiulcer effects independently of their antibacterial activity. ${ }^{19-21}$ Reasons for the $27 \%$ failure rate of triple therapy in eradicating Helicobacter pylori are not completely clear. Compliance may be an important factor - three of the four patients with persistent infection reported significant side effects during treatment so that they took no more than $85 \%$ of medications. This agrees with a recent study by Graham $e t a l^{22}$ in which compliance with antimicrobial treatment was identified as the most important factor in predicting eradication. However, a possible resistance to antibiotics cannot be excluded as a cause of these failures. The reinfection rate at 1 year in patients in whom $H$ pylori had apparently been eradicated with triple therapy was unexpectedly high $(17 \%)$. This may be the result of unrecognised incomplete eradication after acute therapy, but a higher tendency of the infection to recur in these patients compared with those with non-resistant duodenal ulcer cannot be excluded. Healed resistant duodenal ulcers rapidly relapse when treatment is stopped and also tend to recur if maintenance therapy with full doses of $\mathrm{H}_{2}$ blockers at night is used. ${ }^{411}$ The present study shows that the eradication of $H$ pylori significantly reduces relapses of resistant duodenal ulcers, as has already been observed in nonresistant patients, raising important questions as to the possible involvement of $H$ pylori in the development of resistance to $\mathrm{H}_{2}$ antagonists.

Since, in some patients, refractoriness is a prolonged condition ${ }^{23}$ - that is, a long, aggressive phase of the duodenal ulcer disease - long term profound acid inhibition with omeprazole $40 \mathrm{mg}$ daily is often required. ${ }^{5}$ Our findings show that the addition of anti- $H$ pylori agents to the acute antiulcer regimen may be an effective alternative, capable of changing the natural history of this subset of duodenal ulcer patients.

This paper was presented to the annual meeting of the American Gastroenterological Association, San Francisco, California, 10-13 May, 1992 and published in abstract form in Gastroenterology 1992; 102: A147.

1 Bianchi Porro G, Parente F. Duodenal ulcers resistant to $\mathrm{H}_{2-}$ blockers: an emerging therapeutic

2 Bianchi Porro G, Parente F, Lazzaroni M. Tripotassium dicitrato bismuthate (TDB) versus two different doses of dicitrato bismuthate (TDB) versus two different doses of
cimetidine in the treatment of resistant duodenal ulcers. Gut cimetidine in the

3 Lam SK, Lee W, Koo J, Hui WM, Fok KG, Ng M Randomised crossover trial of tripotassium dicitrato bis- 

muthate versus high dose cimetidine for duodenal ulcers
resistant to standard dose of cimetidine. Gut 1984; 25: resistant

4 Tytgat GNJ, Lamers CB, Hameeteman W, Jansen JM, Wilson JA. Omeprazole in peptic ulcers resistant to histamine $\mathrm{H} 2$ receptor antagonists. Aliment Pharmacol Therap 1987; 1: 31-8.

5 Brunner G, Creutzfeldt W, Harke V, Lamberts R. Therapy with omeprazole in patients with peptic ulcerations resistant to extended high-dose ranitidine treatment. Digestion 1988; 39: $80-90$.

6 Bardhan KD, Dhande D, Hinchliffe RFC, Morris P, Thompson M, Carrol NJH, et al. Treatment of ultra A712.

7 Guerreiro AS, Neves BD, Quina MG. Omeprazole in the treatment of peptic ulcers resistant to $\mathrm{H} 2$-receptor treatment of peptic ulcers resistant to H2-receptor
antagonists. Aliment Pharmacol Therap 1990; 4: 309-13.

8 Bardhan KD, Naesdal J, Bianchi Porro G, Petrillo M, Bardhan KD, Naesdal J, Bianchi Porro G, Petrillo M,
Lazzaroni M, Hinchcliffe RFC, et al. Treatment of refracLazzaroni M, Hinchcliffe RFC, et al. Treatment of refractory peptic ulcer with om plaical trial. Gut 1991; 32: 435-8.

9 Bayerdorffer E, Pirlet TH, Sommer A, Kasper G, Ottenjann R. Ofloxacin in der therapie 'resistenter' ulcera
Eine pilot studie. $Z$ Gastroenterol 1988; 26: 155-9.

10 Wagner S, Gebel M, Haruma K, Bär W, Lange P, Freise J, et al. Bismuth sybsalicylate in the treatment of $\mathrm{H} 2$-blocker resistant duodenal ulcers: role of Helicobacter pylori. Gut 1992; 33: 179-83.

11 Parente F, Bianchi Porro G. Long-term treatment of healed refractory duodenal ulcers. Is there any benefit in increasing the dosage of H2-blockers? Ital $f$ Gastroenterol 1989; 21 . the dosage

12 Coghlan JG, Gilligan D, Humphries H, McKenna D, Dooley C, Sweeney E, et al. Campylobactor pylori and recurrence of C, Sweeney E, et al. Campylobactor pylori and recurrence of
duodenal ulcers - a 12 month follow-up study. Lancet 1987; ii: 1109-11.
13 Marshall BJ, Goodwin CS, Warren JR, Murray R, Blincow ED, Blackbourn SJ, et al. Prospective double-blind trial of duodenal ulcer relapse after eradication of Campylobacter duodenal ulcer relapse after eradic
pylori. Lancet 1988; ii: $1437-42$.

14 Rauws EA, Tytgat GN. Cure of duodenal ulcer associated with eradication of Helicobacter pylori. Lancet 1990; 335: 1233-5.

15 George LJ, Borody TJ, Andrews P, Devine M, Moore-Jones $D$, Walton $M$, et al. Cure of duodenal ulcer after eradication of Helicobacter pylori. Med $\mathcal{F}$ Aust 1990; 153: 145-9.

16 Graham DY, Lew GM, Evans DG, Evans DJ, Klein PD. Effect of triple therapy (antibiotics plus bismuth) on duodenal ulcer healing. A randomized controlled trial. Ann Intern Med 1991; 115: 266-9.

17 Miller JP. Colloidal bismuth in the treatment of duodenal ulceration: the benefit for the patient. Scand $\mathcal{7}$ Gastroenterol 1989; 24 (suppl 157): 16-20.

18 Dang Z, Wang K, Tao J, Zhu L, Hu X. A clinical trial comparing colloidal bismuth subcitrate (De-Nol liquid) with sucralfate in the treatment of peptic ulceration. Clin Trials $\mathcal{f}$ 1986; 23: 235-41.

19 Satoh H, Guth PH, Grossmann MI. Role of bacteria in gastric ulceration produced by indomethacin in the rat: cytoprotective action of antibiotics. Gastroenterology 1983; 84: 483-9.

20 Quintero-Diaz M, Sotto-Escobar A. Metronidazole versus cimetidine in the treatment of gastroduodenal ulcer. Lancet 1986; i: 907.

21 Zheng Z, Wang Z, Chu Y, Li Y, Li Q, Lin S, et al. Doubleblind short-term trial of furozolidone in peptic ulcer. (Letter) Lancet 1985; i: 1048-9.

22 Graham DY, Lew GM, Malaty HM, Evans DG, Evans DY, Klein PD, et al. Factors influencing the eradication of Helicobacter pylori with triple therapy. eradication of Helicobacter pylori with triple therapy.
Gastroenterology 1992; 102: 493-6.

23 Bardhan KD. Refractory duodenal ulcer. Gut 1984; 25: 711-7. 